\title{
The Mode of Action of Metronidazole against Trichomonas vaginalis
}

\author{
By D. I. EDWARDS AND G. E. MATHISON \\ Department of Microbiology, Queen Elizabeth College \\ (University of London), Campden Hill, London W.8
}

(Accepted for publication I8 August 1970)

\begin{abstract}
SUMMARY
Metronidazole (I- $\beta$-hydroxyethyl-2-methyl-5-nitroimidazole) inhibited the evolution of hydrogen gas in Trichomonas vaginalis before it inhibited carbon dioxide evolution. Evidence is presented that the phosphoroclastic reaction of the clostridial type was the major mechanism by which both gases were evolved, and it is postulated that metronidazole inhibits, directly or indirectly, the hydrogenase component of the system. A possible mechanism of action is discussed.
\end{abstract}

\section{INTRODUCTION}

The recognition that vaginitis caused by the protozoan Trichomonas vaginalis was a sexually transmitted disease led to intensive efforts to develop a drug which would prove systemically effective against the organism. Previous treatments involving topical therapy, including vinegar douches and methyl violet impregnated tampons, were unsatisfactory, and reinfection of the sexual partners was frequent. The compound I- $\beta$-hydroxyethyl-2-methyl-5-nitroimidazole (metronidazole) (May and Baker Ltd, Dagenham, Essex) proved to be an extremely effective agent, against not only $T$. vaginalis but also a very wide range of other organisms. These include both Grampositive and Gram-negative bacteria, spirochaetes, protozoa, and even certain nematodes. Metronidazole's activity, however, is limited to anaerobic or facultatively anaerobic organisms - a fact which prompted the question: does the drug exert its effect by inhibiting a reaction of fundamental importance to anaerobes? In this communication we present evidence showing the probable site of action of the drug, and postulate the mechanism of action.

\section{METHODS}

Organism. Trichomonas vaginalis strain F. I295 was obtained from an infected patient.

Medium. A modified Bushby's medium (Bushby \& Copp, 1955) at $37^{\circ}$ was used. It was prepared by dissolving $18 \mathrm{~g}$. dehydrated liver infusion (Difco) in I 1 . tryptone soya broth (Oxoid) and filtering. To the filtrate was added $20 \mathrm{~g}$. glucose and I ml. aqueous $5 \%$ calcium pantothenate. The $\mathrm{pH}$ was adjusted to 6.0 if necessary, and the medium sterilized at $5 \mathrm{lb}$./in. ${ }^{2}$ at $109^{\circ}$ for $\mathrm{I} 5 \mathrm{~min}$. Before use, sterile horse serum was added at $20 \%(\mathrm{v} / \mathrm{v})$ to the medium. Subculturing was carried out every $48 \mathrm{~h}$.

Identification of hydrogen gas. This was done chromatographically (Edwards \& Corbett, unpublished). 
Manometric measurements. These were carried out with conventional techniques (Umbreit, Burris \& Stauffer, 1964). Hydrogen evolution was measured by means of paired flasks containing $3 \mathrm{ml}$. liquid with $20 \%$ potassium hydroxide in the centre well of one. Carbon dioxide was determined from total gas evolved minus hydrogen gas evolved. The gas phase was nitrogen, shaking rate 72 strokes/min., and incubation temperature $37^{\circ}$.

Spectrophotometric measurements. These were made with a Unicam SP-600 or Bausch and Lomb Spectronic-20.

Disruption of organisms. This was performed either by grinding packed frozen cells in a Potter-Elvejhem homogenizer or by using a Hughes press (Shandon Scientific Co., London N.W. I0) at $-20^{\circ}$. Debris and unbroken cells were removed by centrifugation at $2000 \mathrm{~g}$ for $5 \mathrm{~min}$.

Phosphoroclastic assays. The increased evolution of hydrogen caused by the addition of $\mathrm{Na}$ pyruvate (Koepsell, 1955) was measured; acetyl phosphate production was measured as the hydroxamate (Lipmann \& Tuttle, 1945); the formate hydrogenlyase reaction was measured by monitoring hydrogen evolution after addition of $\mathrm{Na}$ formate (Stephenson \& Stickland, 1932).

\section{RESULTS AND DISCUSSION}

Metronidazole at $200 \mu \mathrm{g} . / \mathrm{ml}$. (minimum inhibitory concentration, $\mathrm{I} \cdot 0 \mu \mathrm{g} . / \mathrm{ml}$.) added to growing Trichomonas vaginalis in culture resulted in extensive disruption of the organisms. The nucleus, axostyle, and undulating membrane were destroyed within 60 to $75 \mathrm{~min}$.; death occurred at $60 \mathrm{~min}$. and lysis at $75 \mathrm{~min}$. The organisms were judged to be dead if there was no movement of the anterior flagella and undulating membrane, and no growth after $48 \mathrm{~h}$. in fresh medium.

The effect of the drug on evolution of gas from Trichomonas vaginalis in Bushby's medium (Fig. I) was totally to abolish $\mathrm{H}_{2}$ evolution in 15 to 20 min. and $\mathrm{CO}_{2}$ evolution in $60 \mathrm{~min}$, which coincided with death of the organism. The differing sensitivities of the $\mathrm{H}_{2}$ and $\mathrm{CO}_{2}$ evolution to the drug indicated that these gases were not produced by the same reaction. Since the drug affected evolution of the $\mathrm{H}_{2}$ first, we investigated the mechanism of its production in $T$. vaginalis.

There are no data at present available on the mechanisms by which protozoa produce molecular $\mathrm{H}_{2}$ (Review: Baernstein, 1963), but bacterial mechanisms of $\mathrm{H}_{2}$ evolution are well documented (Reviews: Gest, I954; Kornberg, 1959). Of these, the formate hydrogen-lyase reaction, ferredoxin-linked hydrogenases, and the phosphoroclastic reaction of the coliform and clostridial types form the major mechanisms. The pyruvate phosphoroclastic reaction in which pyruvate is converted to acetyl phosphate, $\mathrm{CO}_{2}$ and $\mathrm{H}_{2}$, was investigated by measuring the increased amount of $\mathrm{H}_{2}$ liberated after adding $\mathrm{Na}$ pyruvate $(0.02 \mathrm{M}$ final concentration) to washed flagellates in phosphate buffer $\mathrm{pH} 6.0$ (Fig. 2). Metronidazole $(200 \mu \mathrm{g} . / \mathrm{ml}$.) halved the increase in $\mathrm{H}_{2}$ evolution. Since the coliform type of phosphoroclastic reaction involves formate decomposition, we attempted to identify this reaction in Trichomonas vaginalis. Addition of $\mathrm{Na}$ formate (O.OI to $0.2 \mathrm{M}$ ) to resting-cell suspensions in phosphate buffer, $\mathrm{pH} 6 \cdot 0$, produced no significant effect on $\mathrm{H}_{2}$ evolution. Indeed, at the higher concentration there was a slight inhibitory effect (Fig. 3). This corroborated the findings of Ninomiya \& Suzuoki-Ziro (1952) and suggested the absence of a formate hydrogenlyase system in $T$. vaginalis. 

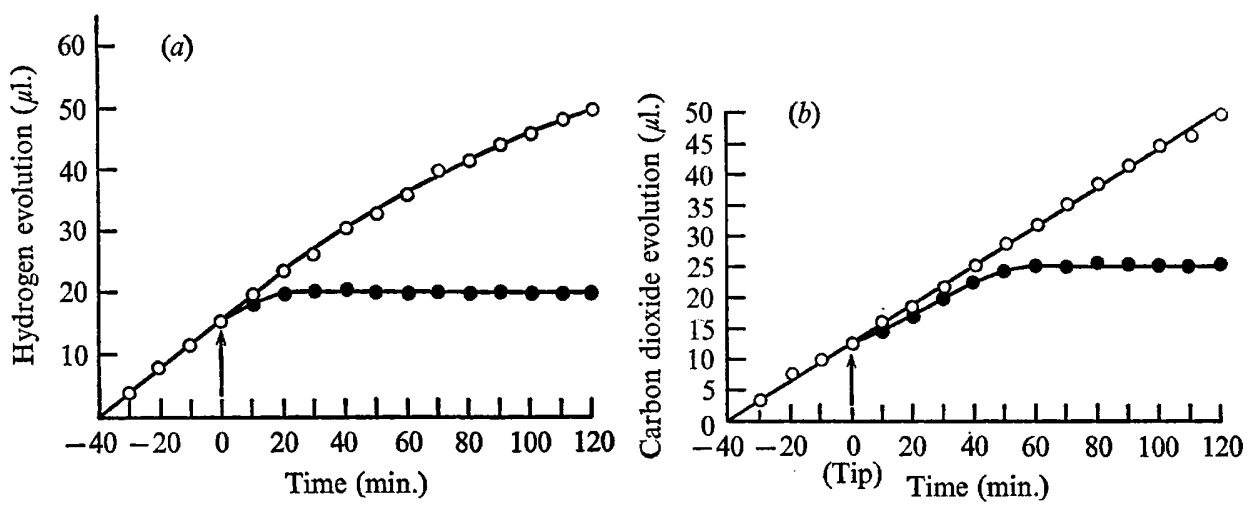

Fig. I (a) The effect of metronidazole on $\mathbf{H}_{2}$ evolution from Trichomonas vaginalis strain F. 1295 . Main flask contained $3 \mathrm{ml}$. of a cell suspension $\left(5 \times 10^{7}\right.$ organisms $/ \mathrm{ml}$.) harvested at $40 \mathrm{~h}$. and resuspended in Bushby's medium at $\mathrm{pH} 6.0$. The side-arm contained either metronidazole in Bushby's medium, to give a final concentration of $200 \mu \mathrm{g} . / \mathrm{ml}$., or medium only. The drug was added from the side-arm at o min. $\mathrm{O}-\mathrm{O}, \mathrm{H}_{2}$ evolution in absence of drug; - $-\mathrm{H}_{2}$ evolution in presence of metronidazole. $(b)$ The effect of metronidazole on carbon dioxide evolution from Trichomonas vaginalis strain F. I295. Data as for Fig. I (a).

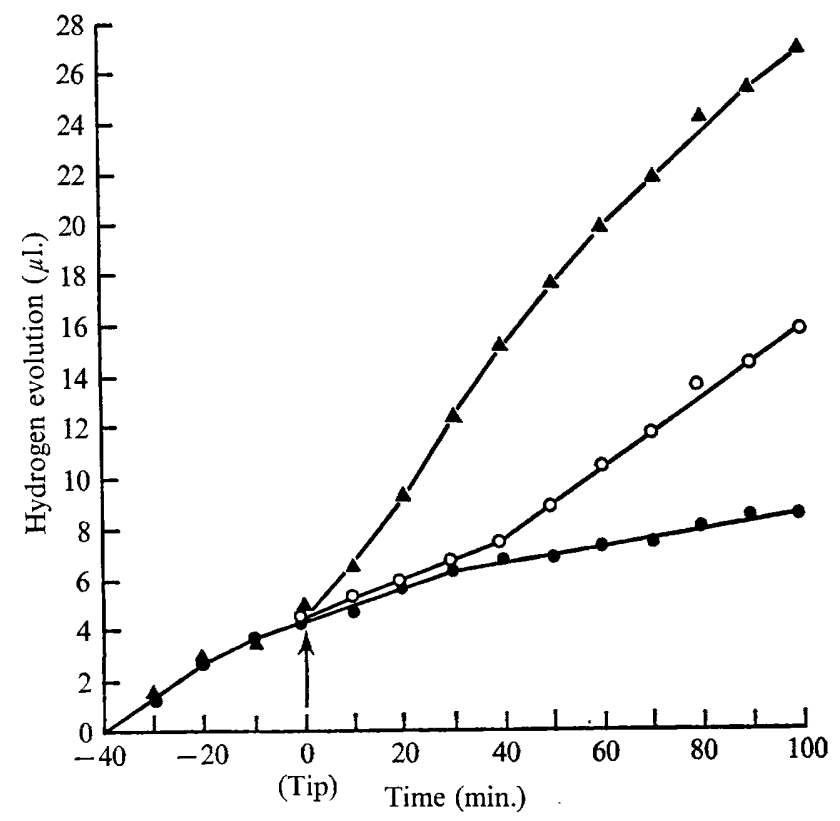

Fig. 2. Effect of metronidazole on the pyruvate phosphoroclastic reaction in Trichomonas vaginalis $\mathrm{F}$. $\mathrm{I} 295$. The main flask contained $3 \mathrm{ml}$. of a cell suspension $\left(5 \times 10^{7}\right.$ organisms $/ \mathrm{ml}$.) harvested at $40 \mathrm{~h}$., and resuspended in $0.1 \mathrm{~m}$-phosphate buffer, $\mathrm{pH} \mathrm{6.0.} \mathrm{The} \mathrm{side-arm} \mathrm{con-}$ tained either phosphate buffer $\left(\mathrm{pH}^{\circ} \cdot{ }^{\circ}\right)$ alone or sodium pyruvate in phosphate buffer, $\mathrm{pH} 6.0$, to give a final concentration of $0.02 \mathrm{M}$, or pyruvate and metronidazole in phosphate buffer to give final concentrations of $0.02 \mathrm{M}$ and $200 \mu \mathrm{g} . / \mathrm{ml}$. respectively. The contents of the side-arm were added at 0 min. $-\longrightarrow$, Endogenous $\mathrm{H}_{2}$ evolution; $\Delta-\longrightarrow, \mathrm{H}_{2}$ evolution as result of pyruvate addition; $\mathrm{O}-\mathrm{O}, \mathrm{H}_{2}$ evolution as a result of pyruvate and metronidazole addition. 
We also measured the rate of acetyl phosphate synthesis caused by adding Na pyruvate to resting-organism suspensions and organism-free extracts. In both we found a fivefold increase in the synthesis of acetyl phosphate from an endogenous level of $0.5 \mu$ moles occurred in $5 \mathrm{~min}$. Metronidazole had no effect on acetyl phosphate synthesis even at concentrations of $800 \mu \mathrm{g} . / \mathrm{ml}$.

This evidence indicated that the phosphoroclastic reaction in Trichomonas vaginalis was of the clostridial rather than the coliform type. Moreover, since the drug inhibited

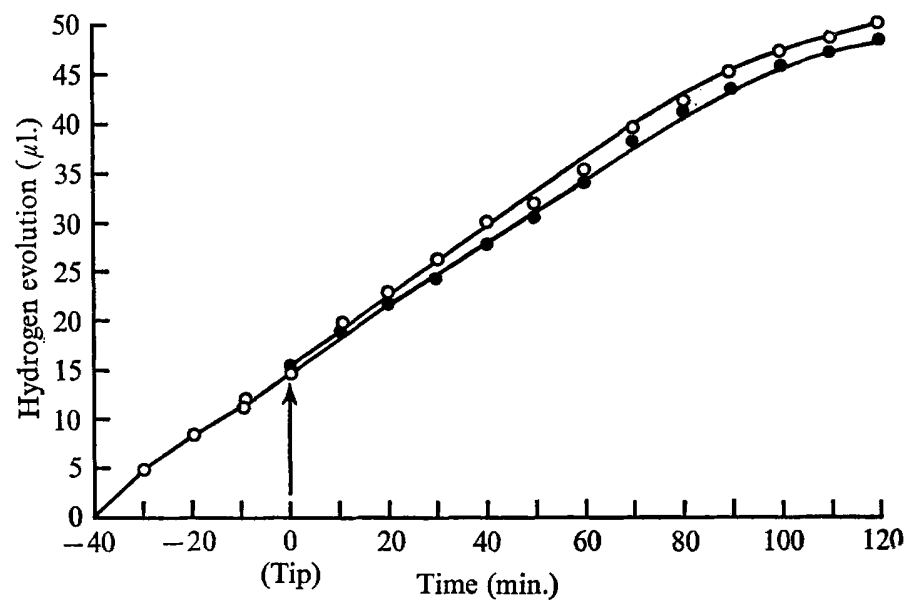

Fig. 3. The effect of formate on hydrogen gas evolution from Trichomonas vaginalis strain F. I 295. Each flask contained $3 \mathrm{ml}$. of $5 \times 10^{7} \mathrm{cells} / \mathrm{ml}$, in $0.1 \mathrm{M}$-phosphate buffer, $\mathrm{pH} \mathrm{6.0.}$

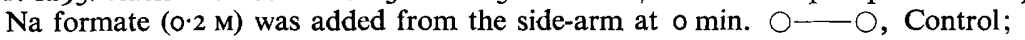
effect of addition of formate.

the evolution of hydrogen, but not the synthesis of acetyl-phosphate, the reaction appeared to proceed by way of at least two enzyme systems similar to the ones postulated for the clostridial system. These are:

(a) Pyruvate + phosphate $\rightarrow$ acetyl phosphate $+\mathrm{CO}_{2}+2 \mathrm{H}^{+}$

(b)

$$
2 \mathrm{H}^{+}+2 \mathrm{e} \rightarrow \mathrm{H}_{2} \text {. }
$$

The first reaction would involve a pyruvate dehydrogenase complex, and the second, a hydrogenase enzyme. The above results also indicated that the site of action of the drug involved the hydrogenase system rather than the dehydrogenase complex.

Hydrogen evolution in micro-organisms is intimately concerned with electron transfer (Gest, 1954). If a hydrogenase type of system was being inhibited in Trichomonas vaginalis by metronidazole then one would expect the drug to affect electron transfer. We therefore investigated the effect of the drug on the ability of the organism to transfer electrons to artificial electron-acceptor dyes.

Methylene blue $(0.48 \mu$ moles in phosphate buffer, $\mathrm{pH} \mathrm{6.0)}$ in a suspension of Trichomonas vaginalis $\left(5 \mathrm{ml}\right.$. containing $10^{8}$ organisms $/ \mathrm{ml}$.) in Thunberg tubes was rapidly decolorized to the leuco form in $4.5 \mathrm{~min}$. Metronidazole $(200 \mu \mathrm{g} . / \mathrm{ml}$. final concentration) slowed decolorization to $12.5 \mathrm{~min}$. Further experimentation showed that there was a linear correlation between drug concentration and the time taken to decolorize the dye (Fig. 4). 
In an organism-free system corresponding to ${ }^{1} 0^{8}$ flagellates in phosphate buffer, with dichlorphenolindophenol (DCPIP) at $100 \mu \mathrm{g} . / \mathrm{ml}$. in place of methylene blue, and with metronidazole at 647 or $323 \mu \mathrm{g}$. $/ \mathrm{ml}$., dye reduction was halted, in 15 and $17 \mathrm{~min}$. respectively (Fig. 5).

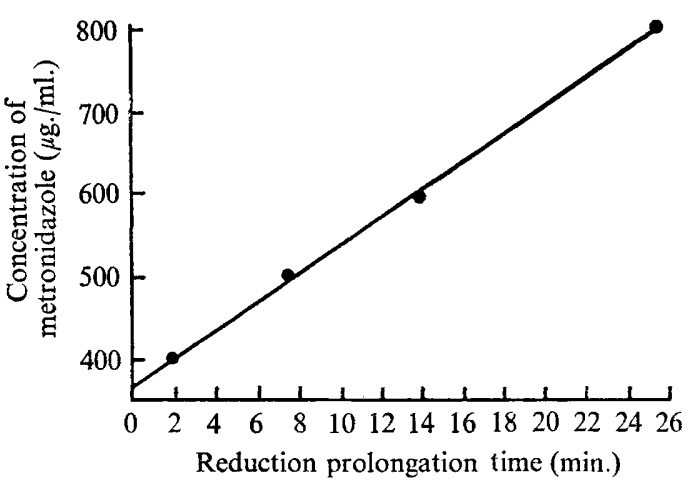

Fig. 4

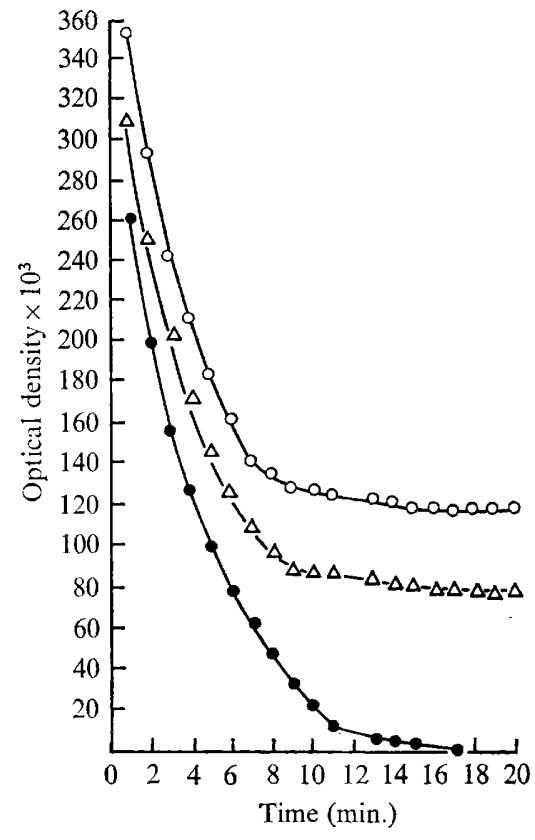

Fig. 5

Fig. 4. The effect of metronidazole on the inhibition of reduction of methylene blue. $0.5 \mathrm{ml}$. Trichomonas vaginalis suspension $\left(1 \times 10^{8}\right.$ organisms $/ \mathrm{ml}$.) in phosphate buffer, $\mathrm{pH} 6 \cdot 0$, were placed in the stopper of a Thunberg tube. The tube contained I $0 \mathrm{ml} .240 \mu \mathrm{M}$-methylene blue in buffer, and $1 \cdot 0 \mathrm{ml}$. metronidazole to give final concentrations of $400,500,600$ and $800 \mu \mathrm{g} . / \mathrm{ml}$. All tubes were evacuated and flushed with nitrogen several times. After incubation at $37^{\circ}$ for $30 \mathrm{~min}$. the contents of stopper and tube were mixed and the time taken for decolorization compared with samples containing no drug.

Fig. 5. The effect of metronidazole on the inhibition of DCPIP reduction by Trichomonas vaginalis organism-free extracts. The system comprised an extract corresponding to $10^{8}$ organisms in $\mathrm{O} . \mathrm{I} \mathrm{M}$-phosphate buffer, $\mathrm{pH} \mathrm{6.5}$; the concentration of metronidazole (where added) was 647 or $323 \mu \mathrm{g} . / \mathrm{ml}$. DCPIP (IO0 $\mu \mathrm{g}$.) was added last and rapidly mixed in a stream of nitrogen. Decolorization of DCPIP was measured at $600 \mathrm{~nm}$. $\triangle \longrightarrow \triangle$, with metronidazole $(323 \mu \mathrm{g} . / \mathrm{ml}) ; \bigcirc-\cdots$, , with metronidazole $(647 \mu \mathrm{g} . / \mathrm{ml}$. $)$

In view of this evidence, we postulated that the drug exerted its effect on the hydrogenase component of the phosphoroclastic reaction. This presumably would be either the enzyme itself, or the electron transfer protein ferredoxin. Since 'one might expect ferredoxin to be present in all organisms that evolve hydrogen in their metabolism' (Mortenson, 1963), and since ferredoxin is only formed in anaerobic organisms (photosynthetic organisms excepted), we suspected a mechanism of action based on the supposed presence of ferredoxin in Trichomonas vaginalis. Metronidazole has a redox (half-wave) potential of $-0.56 \mathrm{~V}$ as measured polarographically, and is therefore more negative than ferredoxin $\left(E_{0}^{\prime}=-0.46 \mathrm{~V}\right)$. The drug can therefore act as a better electron acceptor than ferredoxin, both the nitro group and the imidazole ring con- 
ferring on the drug the properties of an efficient electron 'sink'. Competition for electrons generated by the phosphoroclastic system would thus ensue between the two, and the drug would, as a result, inhibit not only the hydrogenase system, but also other electron transfer mechanisms.

To test this hypothesis, we investigated whether metronidazole had any effect on photosynthesis. Ferredoxin has the role of an electron acceptor and carrier in photosystem I of the photosynthetic reaction, and the drug should inhibit this if it competing with ferredoxin. We found (Edwards \& Schoolar, I970) that the drug inhibited sugar synthesis, and also increased the rate of chlorophyll degradation in sugar cane leaf discs. It had no effect on the Hill reaction (photosystem II), and therefore we presume that its site of action was photosystem I.

The only report to date concerning the mode of action of metronidazole is that of Samuels (1962) who found that the action of the drug on Trichomonas vaginalis was reversed by adding liver infusion or a mixture containing adenine, guanine, hypoxanthine, xanthine and inosine to the medium. He postulated that the drug inhibits nucleic acid synthesis. We find it difficult to reconcile this theory with our data or with the fact that metronidazole affects only anaerobes. Samuels gave no indication of how rapidly the action of the drug was reversed. It seems likely that the effect he observed was not a primary one.

We thank M. J. Parnell of the Applied Physical Chemistry Laboratory, May and Baker Ltd, Dagenham, for the polarographic analysis, and May and Baker Ltd for financial assistance.

\section{REFERENCES}

BaERnsteIn, H. D. (1963). A review of electron transport mechanisms in parasitic protozoa. Journal of Parasitology 49, 12-2I.

BushBy, S. R. M. \& CopP, F. C. (1955). The antitrichomonal activity of amido-nitrothiazoles. Journal of Pharmacy and Pharmacology 7, I I2-I 7 .

Cosar, C. \& Julon, L. (1959). Activité de L'(hydroxy-2-éthyl)I-méthyl-2 nitro-5-imidazole (8.823 R.P.) vis-à-vis des infections expérimentales à Trichomonas vaginalis. Annales de l'Institut Pasteur 96, 238-24I.

EDWARDs, D. I. \& SchOolaR, A. (1970). Inhibition of sugar synthesis, and potentiation of chlorophyll degradation by metronidazole in sugar-cane leaf discs. Zeitschrift für Pflanzenphysiologie(In Press).

GEST, H. (I954). Oxidation and evolution of molecular hydrogen by micro-organisms. Bacteriological Reviews $\mathbf{1 8}, 43-73$.

KoEPSELl, H.J. (1955). In Methods in Enzymology, vol. I, pp. 479-488. Edited S. P. Colowick and N. O. Kaplan. New York: Academic Press.

KornberG, H. L. (I959). Aspects of terminal respiration in micro-organisms. Annual Reviews of Microbiology 13, 49-77.

Lipmann, F. \& Tuttle, L. C. (I945). A specific micromethod for the determination of acyl phosphates. Journal of Biological Chemistry r59, $2 \mathrm{I}-28$.

Mortenson, L. E. (I963). Nitrogen fixation: role of ferredoxin in anaerobic metabolism. Annual Reviews of Microbiology 17, I $15-138$.

NinomiYa, H. \& SuzuoKi-Ziro, (I952). The metabolism of Trichomonas vaginalis with comparative aspects of trichomonads. Journal of Biochemistry (Tokyo) 39, 32I-33I.

Samuels, R. (1962). Reversal of metronidazole inhibition of Trichomonas vaginalis. Journal of Protozoology 48, 30 .

StePhenson, M. \& STiCKLAND, L. H. (1932). Hydrogenlyases: bacterial enzymes liberating molecular hydrogen. Biochemical Journal 26, $712-724$.

Umbreit, W. W., Burris, R. H. \& Stauffer, J. F. (1964). Manometric Techniques. Minneapolis, Minnesota: Burgess Publishing Company. 